\title{
A TRADUÇÃO INTERSEMIÓTICA COMO UM PROCESSO CRIATIVO EM DESIGN: uma análise do cartaz-poema Batmakumba
}

\author{
Samuel Otaviano \\ Pontifícia Universidade Católica do Rio de Janeiro (PUC-Rio) \\ samuelotaviano@gmail.com \\ Vera Lúcia Moreira dos Santos Nojima \\ Pontifícia Universidade Católica do Rio de Janeiro (PUC-Rio) \\ nojima@puc-rio.br \\ Frederico Braida \\ Universidade Federal de Juiz de Fora (UFJF) / Pontifícia Universidade \\ Católica do Rio de Janeiro (PUC-Rio) \\ frederico.braida@ufjf.edu.br
}

\begin{abstract}
Resumo: Este artigo aborda o tema da tradução intersemiótica, proposta por Júlio Plaza, como um processo de criação em Design. O principal objetivo é apresentar uma reflexão sobre um percurso criativo ou um processo projetual fundamentado no escopo teórico da Semiótica e na sua contribuição pragmática. Para tanto, adota-se, como objeto empírico, o cartaz-poema concebido por André Vallias para a música Batmakumba e publicado no livro Tropicália: panis et circenses, dedicado ao álbum musical homônimo. Metodologicamente, partiu-se de uma pesquisa bibliográfica e iconográfica sobre o tema e de uma entrevista com o designer, a fim de se investigar os contextos culturais que serviram de motor para essa composição musical tropicalista, bem como as motivações e a metodologia empregada por Vallias na concepção dessa peça gráfica. Assim, evidenciase como são operacionalizados os diferentes signos (sonoro, visual e verbal) ao longo desse processo e como a tradução intersemiótica alicerça e influencia a lógica projetual e a visualidade do cartaz.
\end{abstract}

Palavras-chave: design, tradução intersemiótica, poesia concreta, tropicalismo, cartaz.

Abstract: This paper addresses the issue of intersemiotic translation proposed by Julio Plaza as a process of creation in Design. The main aim is to present a reflection on a creative path or a design process based on the theoretical scope of Semiotics and its pragmatic contribution. We have adopted the poster-poem conceived by André Vallias for music 
Batmakumba and published in the book Tropicália: panis et circenses, dedicated to the eponymous musical album, as an empirical object. Methodologically we have started with a bibliographic and iconographic research on the topic and an interview with the designer, in order to investigate the cultural contexts that served as engine for this tropicalist musical composition as well as the motivations and methodology employed by Vallias in the graphic design of this piece. At the end it shows how the different signs are operationalized (sonorous, visual and verbal) throughout this process and how the intersemiotic translation underpins and influences the projetual logic and the poster visuality.

Keywords: design, intersemiotic translation, concrete poetry, tropicalism, poster.

\section{INTRODUÇÃO}

Este artigo aborda o tema da tradução intersemiótica, proposta por Júlio Plaza, como um processo de criação em Design. Ele é fruto de parte das reflexões levadas a cabo durante uma pesquisa de mestrado que aborda as relações entre a poesia concreta e o design gráfico. Portanto, para a discussão do tema, adotou-se como, objeto empírico, uma peça gráfica (pôster ou cartaz-poema) concebida pelo designer André Vallias, por meio da qual ele interpreta visualmente (ou traduz intersemioticamente) a música Batmakumba, do álbum Tropicália: panis et circenscis, composta por Gilberto Gil e Caetano Veloso, a qual conjuga elementos do tropicalismo e da poesia concreta.

A partir de um conceito introduzido por Jackobson (1969), Plaza (2003) elabora uma noção ampliada da tradução intersemiótica como sendo a interpretação de um sistema de signos (verbal) por outro (não verbal). Neste artigo, adota-se o mesmo conceito, entendendo o cartaz como um processo de tradução intersemiótica da música Batmakumba. Nesse processo, segundo a visão mais ampla de Plaza (2003, p.10), os suportes e meios empregados também são influenciadores da operação tradutora, portanto, apresenta-se como relevante a discussão das questões intrínsecas e formais (verbais e não verbais) da visualidade dos cartazes, ou ainda, das especificidades inerentes a esses suportes tão caros ao universo do Design Gráfico.

O principal objetivo é apresentar uma reflexão sobre um percurso criativo (ou um processo projetual) fundamentado no amplo escopo teórico da Semiótica (peirceana) e na sua contribuição pragmática. Destaca-se que a Semiótica (PEIRCE, 1977), para além de sua formalidade teórica, possui um ferramental capaz de subsidiar a ação projetual dos designers, como bem evidenciado por Santaella (2005, p.XIII), no livro Semiótica Aplicada, ao afirmar que "além de ser uma teoria do conhecimento, a semiótica também fornece as categorias para a análise da cognição já realizada. Com isso, ela também é uma metodologia".

Metodologicamente, partiu-se de uma pesquisa bibliográfica e iconográfica sobre os contextos culturais que serviram de motor para a composição musical tropicalista e seus atores (CAMPOS, A., PIGNATARI e CAMPOS, H., 2006), bem como sobre os temas da criação projetual no campo do Design, principalmente fundamentada em Lawson (2011), a fim de situar o lugar da tradução intersemiótica dentro das estruturas correntes do pensamento projetual. Para uma maior aproximação entre os pesquisadores e o objeto de estudo, lançou-se mão da técnica 
da entrevista semiestruturada com o designer André Vallias, a qual teve por objetivo investigar as motivações e a metodologia empregada na concepção da peça gráfica, a qual foi submetida à análise semiótica.

Deve-se destacar ainda, em termos introdutórios, que, neste artigo, busca-se relatar como são operacionalizados os diferentes signos (sonoro, visual e verbal) ao longo do processo criativo de Vallias e como os princípios da tradução intersemiótica influenciaram a lógica projetual e a visualidade do cartaz em questão. Ao final, a partir do referencial teórico levantado, da coleta e das análises dos dados empreendidas, conclui-se que a tradução intersemiótica, se compreendida como uma metodologia, pode alicerçar a ação projetual criativa no campo do Design.

\section{TRADUÇÃO INTERSEMIÓTICA COMO UM PROCESSO CRIATIVO}

De acordo com Bürdek (2006, p.225), "design é uma atividade, que é agregada a conceitos de criatividade, fantasia cerebral, senso de invenção e de inovação técnica". O autor ainda afirma, peremptoriamente, que "um processo criativo ele é, sem dúvida". No entanto, subjacente a essas afirmações, está colocada a seguinte questão, que se manifesta diariamente na lida de profissionais como designers, artistas e arquitetos: Como percorrer um caminho sistematizado que garanta resultados eficientes na concepção de um projeto? Obviamente tal questionamento não apresenta uma resposta única e envolve uma série de aspectos subjetivos que só faz revelar a complexidade do universo projetual-criativo.

Mas, se por um lado, a projetação pode ser entendida como uma caixa-preta, por outro, Lawson (2011, p.25) afirma que "projetar é uma habilidade altamente complexa e sofisticada", mas trata-se de "uma habilidade que tem de ser aprendida e praticada". Nesse mesmo sentido, Bürdek (2006, p.225) reforça que "a configuração não se dá em um ambiente vazio, onde se brinca livremente com cores, formas e materiais", pois "cada objeto de design é o resultado de um processo de desenvolvimento, cujo andamento é determinado por condições e decisões".

Diante de tal contexto do campo de ação dos designers, a tradução intersemiótica se apresenta como uma possibilidade norteadora para a criação. A tradução intersemiótica proposta por Plaza (2003) encontra suas origens nos escritos de Jakobson (1969) sobre três tipos possíveis de tradução: a interlingual, a intralingual e a intersemiótica. No entanto é de se ressaltar que Jakobson estava preocupado principalmente com o signo verbal convencional e suas possibilidades de tradução. Logo, assentado principalmente sobre a teoria semiótica peirceana, e subsidiado pelas explorações prático-teóricas levadas a cabo por tantos outros autores como, por exemplo, Walter Benjamin, Paul Valéry, Ezra Pound, Octavio Paz, Jorge Luiz Borges e Haroldo de Campos, Plaza (2003, p.18) parte de uma concepção de tradução muito abstrata, uma vez que afirma que "por seu caráter de transmutação de signo em signo, qualquer pensamento é necessariamente tradução".

Assim, Plaza, por sua vez, busca ampliar o conceito introduzido pelo teórico russo. Recorrendo às palavras de Jakobson, Plaza (2003, p.XI) define a tradução intersemiótica

como sendo aquele tipo de tradução que 'consiste na interpretação dos signos verbais por meio de sistemas não- 
verbais', ou 'de um sistema de signos para outro, por exemplo, da arte verbal para a música, a dança, o cinema ou a pintura', ou vice-versa, poderíamos acrescentar.

A complementação final de Plaza ("ou vice-versa, poderíamos acrescentar") amplia o conceito inicial de tradução intersemiótica, a fim de abarcar as traduções de linguagens não verbais para verbais, o que antes não havia sido definido por Jakobson. Portanto, do escopo teórico explorado por Plaza e fartamente ilustrado com sua "oficina de signos" (PLAZA, 2003, p.95-204), pode-se verificar a potencialidade da tradução intersemiótica como procedimento criativo e projetual. Assim, a tradução intersemiótica descortina-se como uma metodologia que, somadas às demais já estabelecidas no campo do design, fornece subsídios para ampliar as práticas projetuais e criativas.

É a partir desse referencial teórico que se busca, neste artigo, compreender a concepção do cartaz-poema desenvolvido por André Vallias para a música Batmakumba e publicado no livro Tropicália: panis et circenses, dedicado ao álbum musical homônimo. Trata-se de evidenciar os caminhos percorridos por Vallias, adotando-os como um estudo de caso, a fim de revelar a tradução intersemiótica como uma práxis criativa, sobretudo na contemporaneidade fundamentada nas legítimas noções de hibridismos (BRAIDA, 2012), de misturas, de mixagens, de readymades, enfim, da pós-produção (BOURRIAUD, 2009).

\section{O REPERTÓRIO SUBJACENTE À MÚSICA BATMAKUMBA}

Batmakumba é a quinta faixa do lado B do álbum Tropicália: panis et circenscis, composta por Gilberto Gil e Caetano Veloso. Na gravação do disco a faixa é executada pelos dois, junto com Gal Costa e os Mutantes. O arranjo é feito por Rogério Duprat, figura musical central para os tropicalistas por ter trazido a experimentação com música aleatória, concreta e eletrônica (FAVARETTO, 1979, p.24) para suas composições.

Musicalmente, a composição também traz os elementos formadores da "geleia geral brasileira" nas palavras de Décio Pignatari (CAMPOS, 1986, p.288), reunindo a percussão, característica de ritmos afros com elementos da música pop. Um "batuque allegro" (RISÉRIO, 2010, p. 107) imprime o ritmo da canção, acompanhado pelas linhas melódicas do que parece ser uma viola fazendo o contraponto. Como sinaliza o compositor Tuzé de Abreu, esse contraponto, "lembra simultaneamente a música modal nordestina e a música tradicional tocada pelo citar da índia. Por esta via, o som nos remete ainda aos Beatles e aos hippies" (RISÉRIO, 2010, p. 107).

Como um ato de antropofagia, Batmakumba instaura um diálogo entre o erudito e o popular, e, conforme pode ser verificado, formalmente, se aproxima da poesia concreta.

\subsection{Batmakumba e o Tropicalismo, manifestações antropofágicas}

Lançado em 1968, o disco-manifesto Tropicália: panis et circenses, que traz diversas personalidades da cena Tropicalista (figura 1), foi "engendrado coletivamente por Caetano Veloso, Gilberto Gil, Gal Costa, Mutantes, Tom Zé, Torquato Neto, Capinan, e o maestro e arranjador Rogério Duprat" (OLIVEIRA, 2010, p.7). Esse disco surgiu pela preocupação dos artistas envolvidos em buscar algo novo para a música 
popular brasileira. Além destes, também estiveram ligados ao movimento a cantora Nara Leão, Torquato Neto e o artista gráfico, compositor e poeta Rogério Duarte.

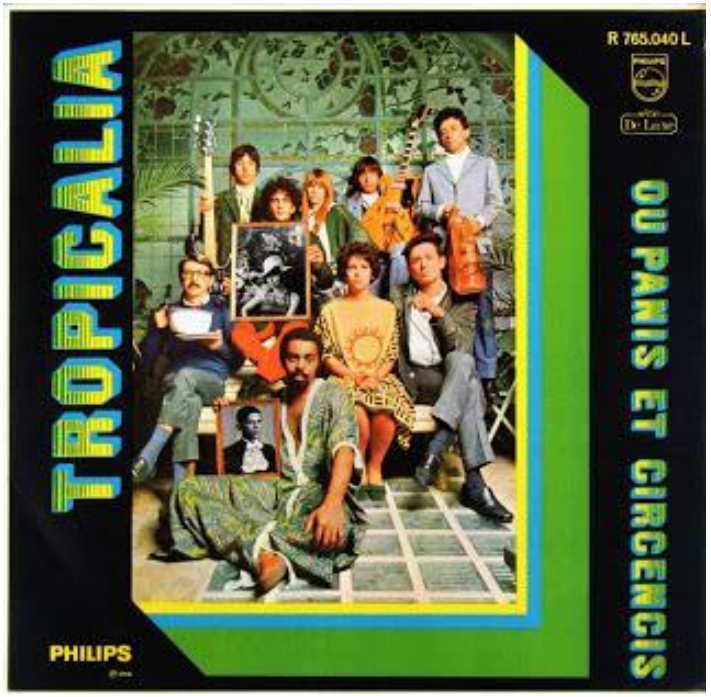

Figura 1 - Capa do disco Tropicália: ou panis et circencis.

Disponível em: <http://tropicalia.com.br/identifisignificados/movimento>. Acesso em: 05 fev. 2014.

O grupo estava empenhado em revolucionar o cenário musical brasileiro do final dos anos de 1960, promovendo e incorporando as mudanças no comportamento e na cultura da juventude daquela época. Eles buscavam "algo que unisse o universalismo e a modernidade da música pop à mais típica música popular brasileira" (RODRIGUES, 2007, p.41). O que causou maior impacto no público, inicialmente formado por universitários e pela plateia dos festivais de música, foi a mistura de elementos tão díspares. Conforme indica Favaretto (1979, p. 24), "quando justapõe elementos diversos da cultura, obtém a suma cultural de caráter antropofágico, em que contradições históricas, ideológicas e artísticas são levantadas para sofrer uma operação desmistificadora".

Nesse procedimento de resgate e reprocessamento cultural foi trazido o nome de Oswald de Andrade e a cultura "antropofágica", inicialmente a partir de Caetano Veloso. Rodrigues (2007, p. 44) assinala que

o contato de Caetano com os textos de Oswald tinha sido possível pela proximidade que ele mantinha com o grupo Noigrandes, formado pelos irmãos Haroldo e Augusto de Campos e Décio Pignatari. Os irmãos Campos mostraram que a obra de Oswald era muito mais do que apenas o texto para teatro. Juntamente com Décio, formavam o núcleo do grupo que lançou em São Paulo, nos anos 1950, o movimento da poesia concreta. Os irmãos, principalmente, tornaram-se referência para o processo de construção das ideias tropicalistas.

\subsection{Batmakumba e o Concretismo: rumos da poesia concreta}

Segundo Campos (1986, p. 287), Batmakumba é a composição tropicalista que mais se aproxima de um poema concreto. Estão presentes os ingredientes do "mosaico 
informativo", tal como define o autor (CAMPOS, 1986, p. 289), típico da paisagem urbana, de modo que a linguagem linear e discursiva é descartada com a adoção da síntese verbal e sonora à maneira dos poetas concretos. Esses procedimentos em comum incluem também "o processo de montagem e a justaposição direta e explosiva de sonoridades vocabulares" (CAMPOS, 1986, p.289). Batmakumba provém da "ideia de que é possível fazer uma poesia rica com um mínimo de palavras" (RISÉRIO, 2010, p. 105), assim como fizeram os percursores da poesia concreta em sua busca por uma poesia de invenção.

Augusto de Campos foi o criador, junto com seu irmão Haroldo de Campos e Décio Pignatari, da poesia concreta nos anos 1950 e fundador do grupo de poesia Noigrandes (CAMARA, 2000, p.10; LAGO, 2012, p. 23-25), que, além desses três integrantes, foi formado também, posteriormente, por Ronaldo Azeredo e José Lino Grünewald (BANDEIRA, 2008, p.9). Os poetas concretos optaram por romper com a poesia tradicional em que os poemas são compostos por versos e adotaram o espaço gráfico da página como agente estrutural da poesia. O Plano Piloto para a Poesia Concreta, texto publicado originalmente em 1958 na quarta edição da revista Noigrandes, editada pelo grupo de poetas concretos, revela o interesse do grupo pela materialidade da palavra, ou seja, seu som, sua forma visual e sua carga semântica, de forma conjunta. $O$ texto/manifesto enuncia ainda que:

O poema concreto comunica sua própria estrutura: estruturaconteúdo. O poema concreto é um objeto em si mesmo, não um intérprete de objetos exteriores e/ou sensações mais ou menos subjetivas. (...) usando o sistema fonético (dígitos) e uma sintaxe analógica, cria uma área linguística específica "verbivocovisual" - que participa das vantagens da comunicação não verbal, sem abdicar das virtualidades da palavra (CAMPOS, 2006, p. 216).

No feixe pelo qual se pretendia traçar essa linha evolutiva ou "salto qualitativo", o grupo formado pelos poetas concretos também se posicionou de modo articulado, no que diz respeito às suas formulações teóricas, com representantes de outras áreas artísticas como a música (Webern, Boulez e Stockhausen), sobre tudo a música concreta e eletrônica, e as artes visuais (através de Mondrian, principalmente, e Malévitch). Seus percursores estão entre os poetas que, já desde o início do século $\mathrm{XX}$, deflagaram o momento que ficou conhecido como a crise do verso. São eles os poetas Mallarmé, Apollinaire, James Joyce, Erza Pound, e. e. Cumings, além dos futuristas e dadaístas como ideologia de vanguarda. No Brasil, os poetas concretos apontam para Oswald de Andrade e João Cabral de Melo Neto como pioneiros e revolucionários em termos de linguagem poética inventiva.

Batmakumba traz em si uma sintaxe espacial do signo verbal e a justaposição direta de elementos sonoros, recorrentes na poesia concreta. Deve-se ressaltar que, a partir das próprias declarações de André Vallias, em uma entrevista, esse reconhecimento está impregnado na sua (re)leitura da música Batmakumba por ocasião da concepção do cartaz-poema. Trata-se, pois, de uma tradução intersemiótica fundamentada no amplo referencial conceitual do Tropicalismo e Concretismo, trasladada do universo da Literatura para o campo do Design. 


\section{O PÔSTER BATMAKUMBA}

O livro para o qual foi feito o pôster faz parte de um projeto maior dirigido e concebido pela pesquisadora Ana de Oliveira. Sua pesquisa e curadoria resultaram em um material disponível no site <www.tropicalia.com.br>. Através desse endereço é possível acessar o hotsite específico do livro. Ele, por sua vez, funciona como meio de divulgação e promoção do livro através da utilização de recursos multimídia que possibilitam assistir a depoimentos em vídeo e ouvir as músicas do disco, além de ser possível fazer o download das imagens dos pôsteres em formato digital.

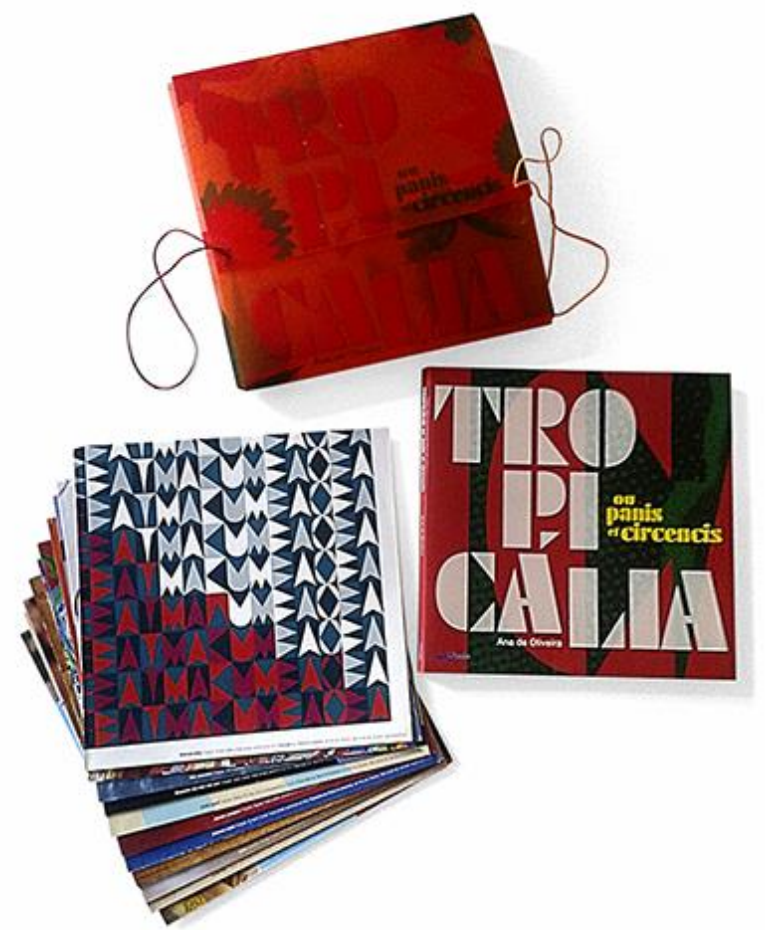

Figura 2 - Case, livro e pôsteres dobrados. Fonte: dos autores.

Em suas características físicas, o "livro-objeto", forma pela qual a publicação é definida no hotsite, consiste em uma obra de 128 páginas, em capa dura, com formato $30,5 \times 30,5 \mathrm{~cm}$ (figura 2). Os pôsteres (dobrados) acompanham o livro dentro de um case próprio. Abertos eles têm $93 \times 62 \mathrm{~cm}$ e cada um dispõe de uma pequena legenda, próxima à margem inferior direita, com o título da respectiva canção do disco, o nome do autor do pôster, e a informação de que o mesmo é parte integrante do livro.

Dentre os pôsteres produzidos, Batmakumba ficou a cargo do poeta, designer e produtor multimídia André Vallias, nascido em São Paulo, em 1963. A trajetória do designer iniciou-se na poesia e, tendo sido influenciado pela poesia concreta, tem interesse particular pela visualidade. Nos anos de 1980, a partir de estudos de proporções na arte, criou seus primeiros poemas visuais, realizando desenhos através de composições matemáticas. Por essa razão, o poeta foi buscar o ferramental para execução destes trabalhos em atividades ligadas a processos gráficos, como a serigrafia e o design. Apesar ter se formado antes em Direito, logo passou a procurar cursos de formação na área de Design, como o curso de tipografia no SENAI. Tudo isso 
foi movido pelo interesse poético, porém, dessa forma, o design surge como uma possibilidade de atuação para o poeta.

Posteriormente, no final dos anos 1980, na Alemanha, André Vallias estabeleceu contato com o filósofo tcheco Vilém Flusser, o "arauto das novas tecnologias na Europa", que foi quem chamou sua atenção para as possibilidades advindas do desenvolvimento da computação. Naturalmente o poeta passou a explorar essa nova ferramenta, primeiro, adaptando poemas originalmente concebidos para serem impressos e, depois, manipulando diretamente recursos nativos do ambiente digital, como por exemplo, a simulação de ambientes tridimensionais e o processamento de dados.

Tendo sido influenciado por este movimento poético a partir do trabalho dos irmãos Campos e Décio Pignatari (VALLIAS, 2013), o poeta que também atua como designer, lança-se como representante não só da poesia visual na atualidade, mas também como articulador da poesia que supera os limites entre verbal e não verbal.

Os trabalhos do autor podem ser encontrados em seu próprio site $<$ http://www.andrevallias.com/> ou no endereço eletrônico da produtora de sites Refazenda <http://refazenda.com/index.php $>$, dirigida por ele.

\subsection{Breve análise semiótica do postêr}

Independentemente do grau de sofisticação com o qual uma análise semiótica possa ser empreendida, quase sempre, os analistas optam por percorrer a lógica das relações internas dos signos. Neste caso específico, ainda que respeitadas as tricotomias peirceanas e os processos de semiose, optou-se por revelar, no âmbito da primeiridade, os aspectos formais do cartaz (sua sintaxe); na secundidade, sua semântica (seus significados); e, na terceiridade, seus aspectos pragmáticos (MORRIS, 1970; QUARANTE, 1994; NIEMEYER, 2003; BRAIDA, 2012). Assim, foi possível abarcar a lógica subjacente ao cartaz e, especialmente, compreender os procedimentos empregados por Vallias durante o processo de tradução intersemiótica.

Primeiramente, deve-se ressaltar que a estrutura do cartaz-poema é formada tendo por base a disposição da letra da música Batmakumba. Essa construção é feita a partir da sucessão de 26 linhas horizontais cuja primeira e a última formam a expressão "batmakumba ye ye batmakumba oba" escrita com letras estilizadas, geometrizadas e sem espaço entre-letras. A partir dessa estruturação inicial, percebese a configuração da letra "K" através do jogo de cores vermelho e magenta que destacam a letra da música do restante da composição formado por diferentes matizes de verde, além do branco (figura 3). De acordo com Gilberto Gil (apud AMARAL, 2009, p. 72), essa estrutura em " $K$ " foi responsável pela substituição da letra " $c$ " (macumba) e adoção do " $y$ " no lugar do "i" (yê yê) como forma de incorporar estrangerismos. 


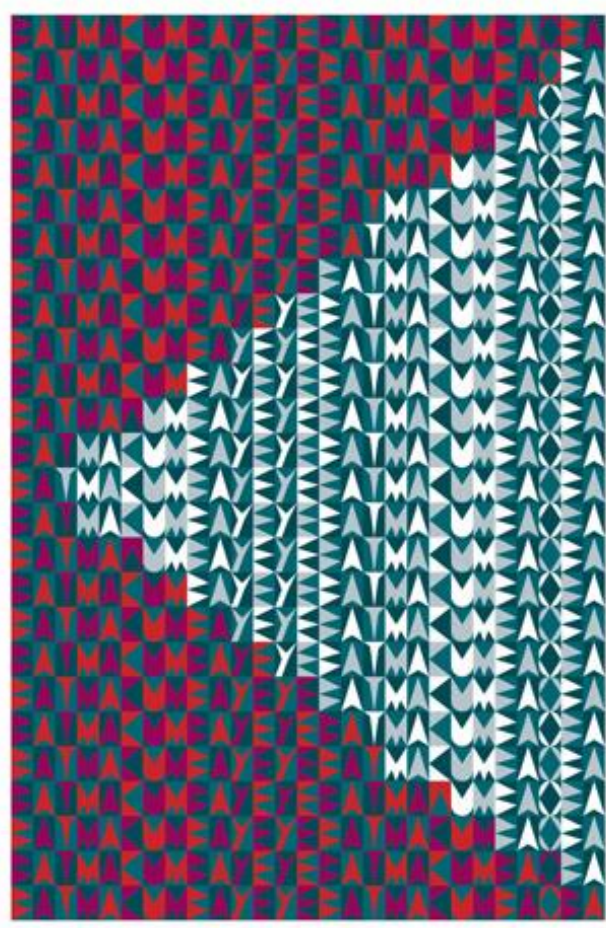

Figura 3 - pôster Batmakumba.

Disponível em: <http://tropicalia.com.br/livro/\#close>. Acesso em: 15 dez. 2013.

Para formar essa letra "K", tal como na letra original, os versos da canção, gradativamente, linha após linha, se reduzem até a sílaba "BA" na linha quatorze. Em seguida, nas linhas restantes, forma-se novamente a expressão inicial. André Vallias realiza assim a síntese visual de Batmakumba a partir da letra da música. Esse procedimento compositivo fundado na composição matemática, na estrutura visual geométrica e no recurso tipográfico é, conforme Rogério Camara (2000), um aspecto central da fase mais ortodoxa da poesia concreta, que vai, segundo Aguilar (2005, p. 22-23), de 1956 até 1960, quando,

em busca dos termos mínimos e da visualidade estrutural, a poesia concreta descarta o uso da cor, tomando em síntese a luz e a sombra - branco e o preto. Esta síntese, as características da composição do poema, "a regularidade dos tipos" e o absoluto controle da disposição dos elementos na página conferem à visualidade da poesia concreta um caráter tipográfico (CAMARA, 2000, p. 89).

É certo que, no cartaz-poema de André Vallias, a cor figura como elemento central na composição, mas, ainda assim essa "visualidade estrutural" é marcante. A estrutura da composição é concebida a partir de um grid de 26 linhas e 27 colunas, cuja célula principal é um retângulo vertical. Esse recurso estrutural é amplamente utilizado no design gráfico, sobretudo naquele que ficou conhecido como design funcionalista derivado de movimentos como o DeStijl (HURLBURT, 1986, p.35). As características desse design funcionalista são apontadas por Camara $(2000$, p.89) ao destacar o vínculo entre o design gráfico e a poesia concreta. Segundo o autor

A organização espacial proposta pelo funcionalismo do Estilo Internacional Suíço é conceitualmente tipográfico: separação de elementos da página por meio de um rígido sistema de grid 
(diagrama), uso uniforme de tipos, economia extrema de formas e racionalização dos elementos gráficos de composição (CAMARA, 2000, p. 89-90).

De acordo com Ambrose (2012, p.27), “o grid é um meio de dispor e relacionar os elementos para facilitar tomadas de decisão", assim como Hurlburt (1986, p.35) assinala que este "organiza o conteúdo específico em relação ao espaço que ele irá ocupar". No caso do cartaz-poema para Batmakumba, em que o grid se dá a partir da configuração da letra da música, este estabelece o espaço que irá comportá-la ao mesmo tempo em que cria a noção de figura e fundo de forma ambígua. A geometrização está presente também na tipografia. Cada letra é geometrizada e estilizada de forma irregular e delimitada pelo retângulo (unidade geradora do grid). Essa disposição das letras permite que elas se ajustem ao grid e criem superfícies uniformes através do uso da cor (figura 4).
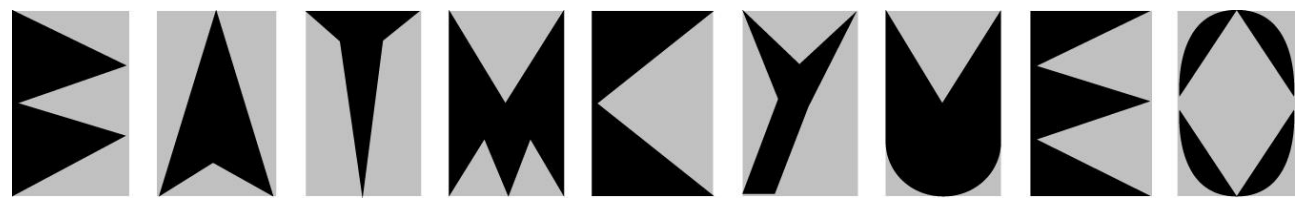

Figura 4 - letras usadas no cartaz-poema de André Vallias.

Fonte: dos autores.

No âmbito da secundidade, deve-se ressaltar a estreita ligação entre o cartaz (entendido como signo) e a letra da música (seu objeto). Trata-se, portanto, de uma relação predominantemente indicial. No entanto, pode-se afirmar que a iconicidade da peça gráfica também é exacerbada, uma vez que se mantém a estrutura espacial original característica, a letra "K", ou o formato das próprias orelhas do Batman. Sendo assim, o cartaz traz em si, predominantemente, as marcas de uma tradução intersemiótica simbólica, mas também, as características indiciais e icônicas.

Por fim, é fundamental ratificar que Vallias compreende a sintaxe da letra da música e a preserva na sua composição. O que pretendia o designer? Não somente a produção de um cartaz, mas sim de um cartaz-poema. Com o jogo tipográficosimbólico, partindo de uma brincadeira em figura e fundo, o designer garante uma conexão evidente entre o representâmen (cartaz) e o seu objeto (letra da música), uma vez que o cartaz é, ele mesmo, pragmaticamente, a própria letra da música traduzida.

\section{DISCUSSÃO DOS RESULTADOS: DA MÚSICA AO PÔSTER, UM PROCESSO DE TRADUÇÃO INTERSEMIÓTICA}

Como pode ser verificado, tanto pelas pesquisas bibliográficas quanto pelo depoimento de André Vallias, ratificados pelas análises empreendidas, o cartaz-poema Batmakumba pode ser compreendido como uma tradução intersemiótica da letra da música de Gilberto Gil e Caetano Veloso. Vale reforçar que esse processo funciona como um ato de criação, pois a tradução intersemiótica instaura, por ela mesma, o ato criativo que traz em si.

Campos, A., Pignatari e Campos, H. (2006, p. 133-134), ao estabelecerem o caráter evolutivo do movimento da poesia concreta, contrapõem o que chamam de "estrutura orgânica" à estrutura concebida a partir de uma opção seletiva crítica adotada pelo poeta concreto. É assim que a operação criadora, matematicamente 
planejada, irá se constituir como "racionalismo construtivo". O autor, citando Mario Pedrosa, aproxima o poeta do pintor concreto afirmando, sob esta perspectiva criativa, que "a fenomenologia da composição cederá a uma verdadeira matemática da composição". De acordo com Risério (2010, p. 105),

é justamente a essa "matemática inspirada", para lembrar outra formulação poundiana, que se filia, em seu procedimento construtivo verbal, a composição "Batmakumba" (RISÉRIO, 2010, p. 105).

Essa semelhança de procedimentos construtivos entre os poetas concretos e os tropicalistas manifesta-se em Batmakumba. E, a partir desses pressupostos, Vallias interpreta o poema-letra de música e o traduz em seu poema-cartaz, estabelecendo conexões sintáticas, semânticas e pragmáticas.

$\mathrm{Na}$ realidade, ao longo da história, pode-se perceber que são fartos os exemplos das constituições de novos produtos e sistemas de significação propostos a partir da tradução intersemiótica. Rizolli (2012, p.2), por exemplo, ao investigar os métodos criativos, os modos produtivos e as determinações funcionais propostas por Pablo Picasso, Francis Picabia, Salvador Dalí e Andy Warhol, identificou que, em diversas situações, trata-se de hibridismos entre "a deliberada criatividade do artista e a aplicada funcionalidade do designer" que, em última instância, pode ser entendidos como operações de traduções intersemióticas.

Assim, o cartaz de André Vallias, estudado como um caso particular de tradução intersemiótica, apresenta-se, para além de uma peça gráfica que se encerra em sua própria visualidade, como uma metodologia projetual a qual pode ser empregada por designers em seus processos de criação.

\section{CONSIDERAÇÕES FINAIS}

O que se buscou neste artigo, foi revelar um caminho adequado para dar conta de parte da complexidade dos atos criativos, sobretudo o campo do design gráfico. Da análise crítica do processo de tradução intersemiótica entre um cartaz e uma letra de música, verificou-se a possibilidade de gerar novos sistemas de signos a partir de outros já constituídos, seja no campo do design ou nas fronteiras entre esse e outros campos do conhecimento e das artes.

Com o estudo de caso do cartaz Batmakumba, de André Vallias, espera-se ter evidenciado um lugar potencial para a tradução intersemiótica nos processos projetuais e criativos. Ressalta-se que não se trata de uma receita, mas de um percurso possível para a construção de novos sistemas sígnicos concebidos a partir de outros preexistentes. A tradução intersemiótica revela-se, pois, como uma metodologia projetual fundamentada no arcabouço teórico da Semiótica de Peirce, sobretudo vinculada à concepção do design como um processo comunicativo e como um fenômeno de linguagem.

\section{Agradecimentos}

Os agradecimentos são direcionados para a FAPEMIG (Fundação de Amparo a Pesquisa do Estado de Minas Gerais), pelo apoio financeiro e logístico que possibilitou a apresentação deste trabalho. 


\section{REFERÊNCIAS}

AGUILAR, Gonzalo. Poesia Concreta Brasileira: As Vanguardas na Encruzilhada Modernista. São Paulo: Editora da Universidade de São Paulo, 2005.

AMARAL, J. F. B. Arnaldo Antunes - 0 corpo da Palavra. 2009. 109 f. Dissertação (mestrado) - Universidade Federal do Rio de Janeiro - UFRJ, Curso de PósGraduação em Letras Vernáculas.

AMBROSE, Gavin. Layout. - 2a ed. - Porto Alegre: Bookman, 2012.

BANDEIRA, João; BARROS, Lenora (Org.). Poesia concreta: o projeto verbivocovisual. São Paulo: Artemeios, 2008.

BOURRIAUD, Nicolas. Pós-produção: como a arte reprograma o mundo contemporâneo. São Paulo: Martins Fontes, 2009.

BRAIDA, Frederico. A linguagem híbrida do design: um estudo sobre as manifestações contemporâneas. 2012. 298 f. Tese (doutorado) - Pontifícia Universidade Católica do Rio de Janeiro, Curso de Pós-Graduação em Design.

BÜRDEK, Bernhard E. História, teoria e prática do design de produtos. São Paulo: Edgard Blücher, 2006.

CAMARA, Rogério. Grafo-sintaxe concreta: o projeto Noigrandes. Rios Ambiciosos, 2000.

CAMPOS, Augusto de. Balanço da Bossa e outras bossas. São Paulo: Perspectiva, 1986.

CAMPOS, Augusto de; PIGNATARI, Décio; CAMPOS, Haroldo de. Teoria da Poesia Concreta: textos críticos e manifestos. Cotia, SP: Ateliê Editorial, 2006.

FAVARETTO, Celso F. Tropicália: alegoria, alegria. São Paulo: Kairós, 1979.

HURLBURT, Allen. Layout: o design da página impressa. - 2a ed. - São Paulo: Nobel, 1986.

JAKOBSON, Roman. Linguística e comunicação. 2.ed. São Paulo: Cultrix, 1969.

LAGO, Bia Corrêa do. Umas Palavras: 15 entrevistas memoráveis / [org.] Bia Corrêa do Lago. Rio de Janeiro: Capivara, 2012.

LAWSON, Bryan. Como arquitetos e designers pensam. São Paulo: Oficina de Textos, 2011.

MORRIS, Charles William. Foundations of the theory of signs. Chicago: The University of Chicago Press, 1970.

NIEMEYER, Lucy. Elementos de semiótica aplicados ao design. Rio de Janeiro: $2 A B$, 2003.

OLIVEIRA, Ana de. Tropicália ou Panis et circensis. São Paulo: Iyá Omin, 2010.

PEIRCE, Charles Sanders. Semiótica. São Paulo: Perspectiva, 1977.

PLAZA, Julio. Tradução Intersemiótica. São Paulo: Perspectiva, 2008. (Estudos, 93).

QUARANTE, Danielle. Éléments de design industriel. 2.ed. Paris: Polytechnica, 1994.

RISÉRIO, Antonio. Batmakumba. In: OLIVEIRA, Ana de. Tropicália ou Panis et circensis. São Paulo: Iyá Omin, 2010. P. 104-107.

RIZOLLI, Marcos. Artistas-designers do século XX: um inventário semiótico. Tríades. Rio de Janeiro, $\quad$ n.2, Disponível em: <http://www.revistatriades.com.br/blog/wp-

content/uploads/2012/01/marcosrizolli_dez.pdf>. Acesso em: 10 dez. 2013.

RODRIGUES, Jorge Caê. Anos fatais: design, música e tropicalismo. Rio de Janeiro: $2 A B$, 2007. Novas Ideias, 2007.

SANTAELLA, Lucia. Semiótica aplicada. 2. reimp. São Paulo: Pioneira Thomson Learning, 2005.

VALLIAS, André. Entrevista presencial concedida ao autor. Rio de Janeiro, 2013. Arquivo de áudio em formato $\mathrm{mp} 3$. 